\title{
A de novo monoclonal immunoglobulin deposition disease in a kidney transplant recipient: a case report
}

\author{
Benjamin Savenkoff ${ }^{*}$, Perrine Aubertin ${ }^{2}$, Marc Ladriere ${ }^{1}$, Cyril Hulin ${ }^{3}$, Jacqueline Champigneulle ${ }^{4}$ and Luc Frimat ${ }^{1}$
}

\begin{abstract}
Introduction: Myeloma following kidney transplantation is a rare entity. It can be divided into two groups: relapse of a previous myeloma and de novo myeloma. Some of these myelomas can be complicated by a monoclonal immunoglobulin deposition disease, which is even less common. Less than ten cases of monoclonal immunoglobulin deposition disease after renal graft have been reported in the literature. The treatment of these patients is not well codified.

Case presentation: We report the case of a 43-year-old white European man who received a renal transplant for a nephropathy of unknown etiology and developed a nephrotic syndrome with kidney failure at 2-years follow-up. We diagnosed a de novo monoclonal immunoglobulin deposition disease associated with a kappa light chain multiple myeloma, which is a very uncommon presentation for this disease. Three risk factors were identified in this patient: Epstein-Barr virus reactivation with cytomegalovirus co-infection; intensified immunosuppressive therapy during two previous rejection episodes; and human leukocyte antigen-B mismatches. Chemotherapy treatment and decrease in the immunosuppressive therapy were followed by remission and slight improvement of renal function. A relapse occurred 8 months later and his renal function worsened rapidly requiring hemodialysis. He died from septic shock 4 years after the diagnosis of monoclonal immunoglobulin deposition disease.
\end{abstract}

Conclusions: This rare case of post-transplant lymphoproliferative disorder with an uncommon presentation illustrates the fact that treatment in such a situation is very difficult to manage because of a small number of patients reported and a lack of information on this disease. There are no guidelines, especially concerning the immunosuppressive therapy management.

Keywords: Light chain deposition disease (LCDD), Myeloma, Nephrotic syndrome, Post-transplant lymphoproliferative disorder (PTLD), Renal graft

\section{Introduction}

Myeloma following kidney transplantation is a rare entity. Approximately 30 cases have been described in the literature. The disease either occurs in the rare situation of recurrent myeloma - initial degradation of native renal function caused by a myeloma followed by complete remission allowing kidney transplantation - or in a context of a post-transplant lymphoproliferative disorder (PTLD) [1], that is, de novo myeloma. Renal monoclonal immunoglobulins deposits can complicate the hematological

\footnotetext{
* Correspondence: benjamin.savenkoff@orange.fr

${ }^{1} \mathrm{CHU}$ Nancy-Brabois - Service de Néphrologie, Nancy, France

Full list of author information is available at the end of the article
}

disease in many different ways (cast nephropathy, amyloid light chain amyloidosis, non-amyloid fibrillary glomerulonephritis, immunotactoid glomerulonephritis and so on), all of them resulting in renal function impairment. One of these renal monoclonal immunoglobulins deposits pathologies is called monoclonal immunoglobulin deposition disease (MIDD), also known as Randall disease [2]. De novo MIDD is very exceptional in kidney transplant recipients, less than ten cases have been reported in the literature [3-6]. We present the case of a patient who underwent kidney transplantation for nephropathy of unknown etiology, then developed de novo MIDD associated with kappa light chain multiple myeloma, revealed by a nephrotic syndrome and kidney failure. 


\section{Case presentation}

A 43-year-old white European man was referred to our unit with an early end-stage renal failure disclosed by asthenia and malignant hypertension. At admission, laboratory tests showed: serum creatinine $7.0 \mathrm{mg} / \mathrm{dL}$; blood urea nitrogen $200 \mathrm{mg} / \mathrm{dL}$; proteinuria $1.5 \mathrm{~g} / 24$ hours (albuminuria $75 \%$ ); negativity of Bence-Jones proteinuria; microscopic hematuria; normal immunology tests; normal serum protein electrophoresis (absence of monoclonal gammopathy and no hypogammaglobulinemia). His renal arteries were normal at the Doppler ultrasound. We tried to perform a renal biopsy but we failed because we only got fat tissue. He required peritoneal dialysis.

Eleven months later, a cadaveric renal graft was transplanted (pediatric donor who died from hemorrhagic stroke; cytomegalovirus (CMV), status: donor+/recipient+). Epstein-Barr virus (EBV), herpes simplex virus, and toxoplasmosis serologies were positive; other serologies were negative. The human leukocyte antigen (HLA) compatibility was: A2-A29/B45-B51/DR1-DR14/DQ5-DQ5 (patient); A2-A24/B7-B60/DR13-DR15/DQ5-DQ6 (donor). A serum protein electrophoresis was performed in the patient at this time and was normal (absence of monoclonal gammopathy and no hypogammaglobulinemia).

The initial immunosuppressive treatment included antilymphocyte serum. The post-transplantation period was uneventful with diuresis on day 1 and serum creatinine $1.7 \mathrm{mg} / \mathrm{dL}$ (Modification of Diet in Renal Disease, MDRD, formula: $48 \mathrm{~mL} / \mathrm{minute} / \mathrm{m}^{2}$ ) at discharge. The immunosuppressive treatment at discharge was: prednisone $(20 \mathrm{mg}$ daily); ciclosporin (175mg twice a day); mycophenolate (1000mg twice a day).

Two months after transplantation, CMV reactivation required oral treatment with valganciclovir and a decrease in the immunosuppressive doses: prednisone (5mg daily); ciclosporin $110 \mathrm{mg}$ twice a day; mycophenolate $(1000 \mathrm{mg}$ twice a day).

Seven months after transplantation, he was hospitalized for renal function decline. A graft biopsy was performed and showed borderline acute rejection; immunofluorescence for light and heavy immunoglobulin chains was negative. Treatment with methylprednisolone (five intravenous boluses at decreasing doses) was followed by a decrease in serum creatinine which returned to its initial level $(1.3 \mathrm{mg} / \mathrm{dL})$.

He was hospitalized for the same reasons 18 months after transplantation. The graft biopsy again showed borderline acute rejection; immunofluorescence for light and heavy immunoglobulin chains was again negative. Treatment was again methylprednisolone (five intravenous boluses at decreasing doses), with the same results.

His general status declined 22 months after transplantation. At admission, an examination revealed rapid weight loss, long-standing productive cough, and herpes zoster with a Ramsay Hunt syndrome. His renal function was altered: serum creatinine $2.4 \mathrm{mg} / \mathrm{dL}$ (MDRD $31 \mathrm{~mL} /$ minute/ $1.73 \mathrm{~m}^{2}$ ); proteinuria $7 \mathrm{~g} / 24$ hours ( $6 \mathrm{~g}$ albumin). The three main hypotheses explaining this de novo nephrotic syndrome in this kidney transplant recipient were, by reported frequency $[7,8]$ : allograft glomerulopathy; recurrent baseline nephropathy; and de novo glomerulopathy.

The immunosuppressive treatment was diminished because of a herpes zoster flare-up (prednisone $5 \mathrm{mg}$ twice a day, ciclosporin $100 \mathrm{mg}$ twice a day, mycophenolate $500 \mathrm{mg}$ twice a day). He also received oral valaciclovir.

A new graft biopsy was performed and revealed severe glomerular involvement with flocculocapsular synechiae, scleronodular mesangial thickenings involving 13 of 30 glomeruli analyzed, a few zones of segmental and focal hyalinosis, peritubular thickening and interstitial fibrosis with tubular atrophy estimated at $50 \%$. The tubules were free of myelomatous casts. Immunofluorescence disclosed monotypic kappa light chain immunoglobulin deposits in the glomerular mesangium and peritubular spaces. Congo red staining was negative. However, electron microscopic examination was not performed because we did not expect to find monoclonal immunoglobulin deposits and thus we fixated no specific sample in glutaraldehyde. Considering this biopsy, the diagnosis of MIDD was retained [2]. Serum protein electrophoresis revealed a monoclonal gammopathy with a kappa light chain monoclonal peak at 964mg/L (free light chains assay Freelite ${ }^{\bullet}$ produced by Binding Site ${ }^{\circ}$, kappa/lambda ratio at 102, hypogammaglobulinemia, and hypoalbuminemia at $25 \mathrm{~g} / \mathrm{L}$ related to the nephrotic syndrome. A bone marrow aspiration showed $16 \%$ atypical plasma cells (high nucleus to cytoplasm ratio, mature chromatin, nuclear inclusions) corresponding to a kappa monotypic clonal population. These results confirmed the diagnosis of MIDD secondary to kappa light chain multiple myeloma without extrarenal event. Polymerase chain reaction on total blood samples was positive for EBV at the time of diagnosis, signaling systemic EBV reactivation. However no direct EBV research was performed on the bone marrow examination at this moment. We considered that both myeloma and MIDD occurred de novo in this patient because there was no evidence of plasma cell dyscrasia before, and the two previous graft biopsies showed no immunoglobulin deposits.

He was transferred to the hematology unit and treated for this PTLD by chemotherapy (bortezomib plus dexamethasone). For the immunosuppressive treatment, mycophenolate was discontinued progressively and ciclosporin was pursued, as was prednisone on days without dexamethasone.

The treatment was followed by remission of his myeloma with a decrease in the serum light chains and a slight improvement in renal function; serum creatinine improved from 3.5 to $2.7 \mathrm{mg} / \mathrm{dL}$. 
He had a relapse with an elevated light chains level 32 months after transplantation. A second chemotherapy regimen was given (bortezomib-cyclophosphamide-dexamethasone) with decreased immunosuppression (ciclosporin reduced to $75 \mathrm{mg}$ twice a day).

Nevertheless his renal function worsened rapidly and he required hemodialysis 3 years after transplantation. He received a third line of chemotherapy (lenalidomid plus dexamethasone) for a second relapse of his myeloma 54 months after transplantation.

It is important to notice that we performed a follow-up bone marrow aspiration at this period that confirmed the myeloma relapse and showed $10 \%$ of tumoral monoclonal plasmocytes. The in situ hybridization did not permit us to find EBV in these tumoral cells.

He finally died from septic shock in a context of postchemotherapy medullary aplasia at the age of 50, 4 years after myeloma diagnosis and approximately 6 years after transplantation (Figures 1, 2, 3, 4 and 5).

\section{Discussion}

Post-transplant myeloma is a rare disease and can occur in the situation of recurrent myeloma (diagnosed or not prior to transplantation) or can occur de novo. Several problems are emphasized by this case report.

First of all, it can be difficult to assert the de novo character of myeloma because sometimes a kidney biopsy was not performed or was not contributive before transplantation. Moreover, as shown by Balamuthusamy et al. in their case report [6] it can be a latent pre-transplant form of myeloma or even a simple monoclonal gammopathy of undetermined significance that may transform into an aggressive myeloma after transplantation in the context of immunosuppressive therapy. In our case we considered

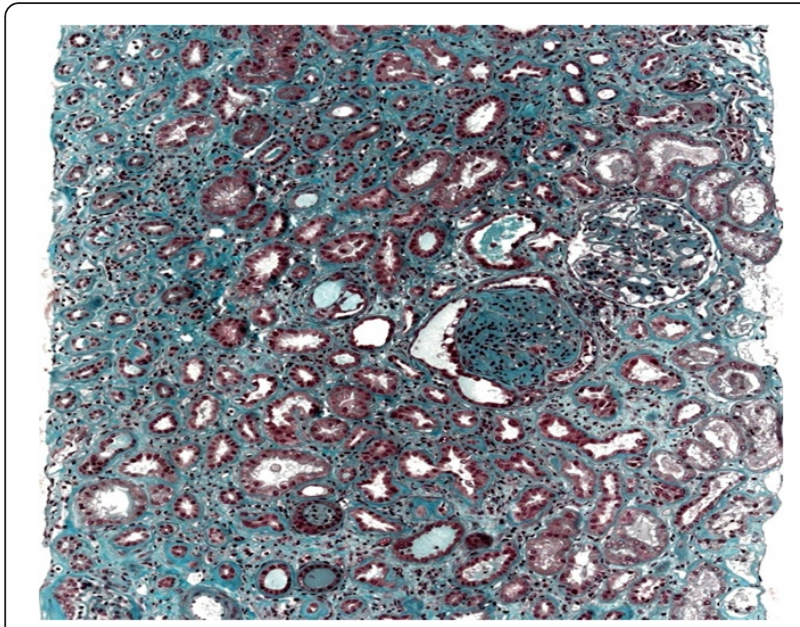

Figure 1 Standard stain, low magnification: interstitial fibrosis with tubular atrophy and presence of a sclerous glomerulus with flocculocapsular synechiae.

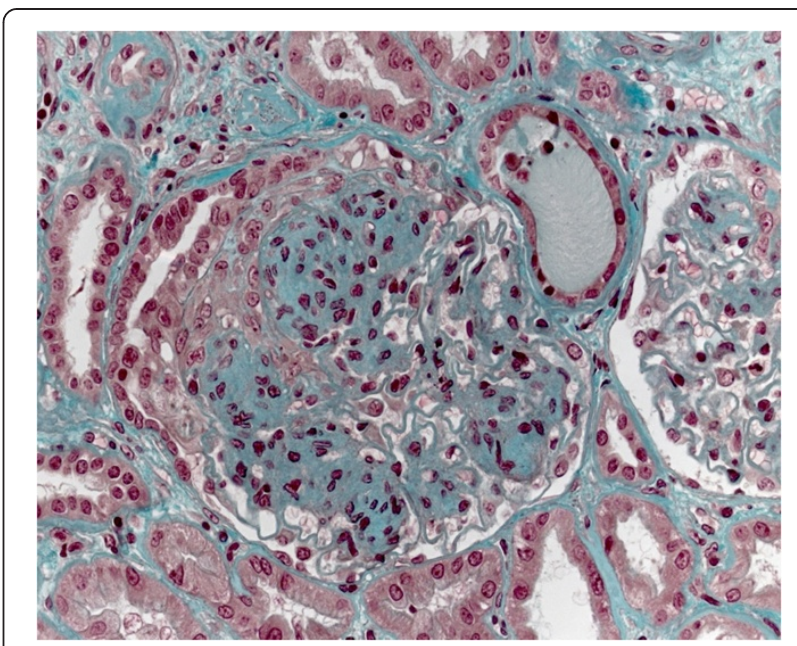

Figure 2 Standard stain, higher magnification than in Figure 1: nodular glomerulosclerosis and presence of a protein cylinder in one tube (related to the severe nephrotic syndrome).

that both myeloma and MIDD occurred de novo after the renal transplantation because we had strong arguments to assert that there was no plasma cell dyscrasia and no evidence of monoclonal immunoglobulin in the patient's blood or urine when he was referred to our unit for the first time. In addition, two graft biopsies were performed when his renal graft function worsened and there was no evidence of monoclonal immunoglobulin deposits. As shown by Taneda et al. in their article [5] there is a gradual progression of kappa light chain deposition in the renal allograft and these deposits are usually present within the kidney a long time before it becomes clinically symptomatic.

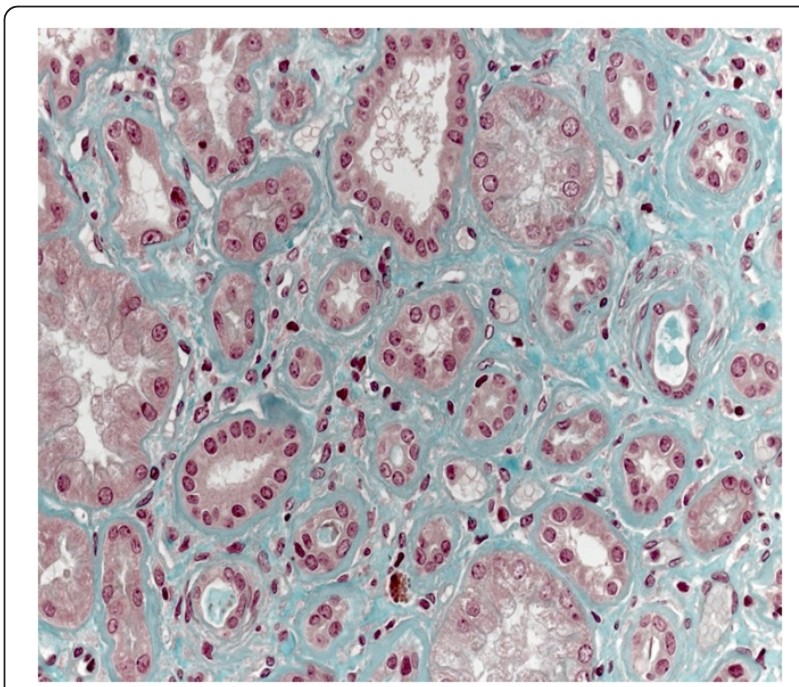

Figure 3 Standard stain, same magnification as in Figure 2: major baseline membrane thickening. 


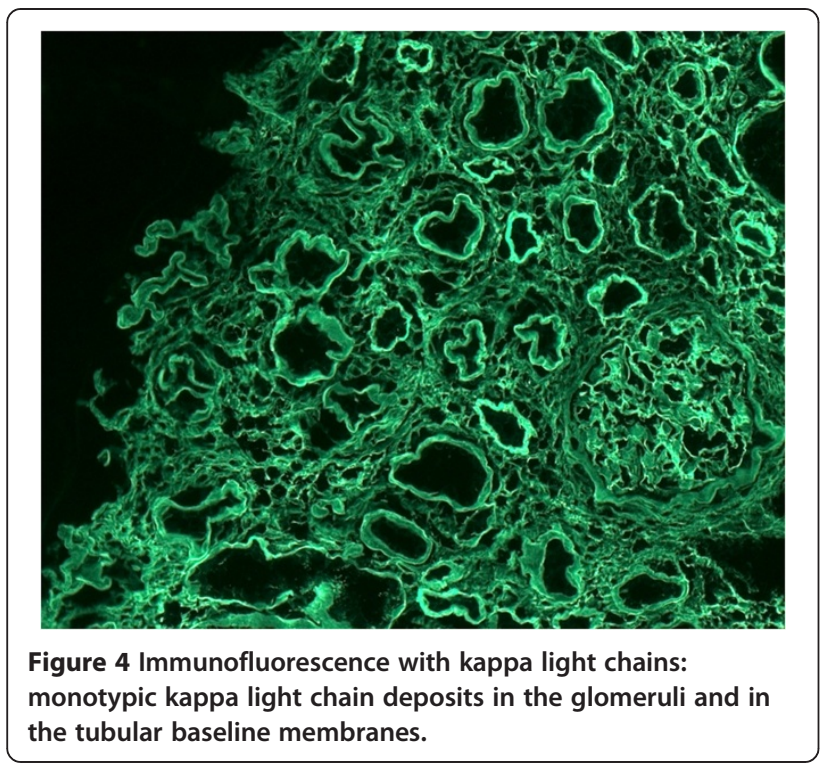

The de novo form of myeloma is a B-cell PTLD, like diffuse large B-cell lymphoma [1]. The incidence is low, accounting for 3 to $13 \%$ of all PTLDs depending on the series $[9,10]$. Patients are older compared to the lymphoma group [9]. Risk factors are still not clear but they seem to be the same as for all PTLDs:

- primary EBV infection or EBV reactivation (with $\mathrm{CMV}$ and hepatitis $\mathrm{C}$ virus co-infections identified as risk cofactors) $[9,11]$;

- major immunosuppressive treatment; in particular, inductive antilymphocyte serum and long-term anti-calcineurin drugs whereas other immunosuppressive agents are less associated with this risk or

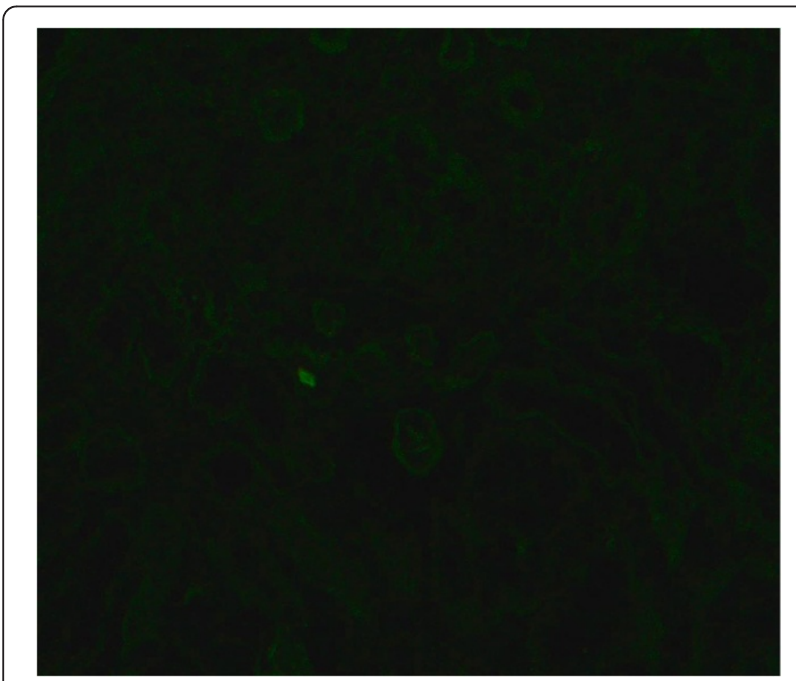

Figure 5 Immunofluorescence with lambda light chains: absence of deposits (negative control). even have a protective effect as observed in certain studies with antimetabolites and anti-mammalian target of rapamycin drugs such as sirolimus) $[9,12,13]$;

- HLA incompatibility, especially for HLA-B (direct effect by creation of a latent antigen conflict with secretion of lymphoproliferative cytokines and indirect effect by causing graft rejection requiring more intense immunosuppression) [14-16].

Our patient presented all the above risk factors: EBV reactivation with CMV co-infection; intensified immunosuppressive therapy during both rejection episodes; HLA mismatches, particularly for HLA-B.

These risk factors should be systematically searched among patients with de novo plasma cell dyscrasia, which is rarely emphasized in the literature.

Regarding the management strategy for these patients, a systematic screening for EBV in tumor plasma cells using an in situ hybridization technique would be advisable because the majority of these hematological diseases are virus related [17]. If viral reactivation is documented, an antiviral treatment can be proposed; in particular, ganciclovir because Foscavir (foscarnet) is nephrotoxic $[18,19]$. In our case, direct EBV tests were not performed at the time of diagnosis and no antiviral treatment was given.

A third problem concerning de novo myeloma or MIDD after transplantation is that the treatment strategy is not well codified.

It would be probably advisable to diminish the immunosuppressive treatment because several studies have demonstrated that PTLDs regress after decreasing anti-rejection treatments [12]. No clear guidelines are available, but it would appear reasonable to reduce the anti-calcineurin dose first because several studies have linked these agents with a higher relative risk of PTLD compared with other treatments $[9,13,20]$. In our patient, the mycophenolate dose was reduced first and ciclosporin was maintained at the same dose, which illustrates the heterogeneous management strategy, especially concerning the immunosuppressive treatment. This immunosuppressive treatment strategy is not well clarified in the literature dealing with de novo plasma cell dyscrasias. Usually, immunosuppressive therapy is rapidly stopped when graft function worsens because of a very high infection risk compared to the benefit of the treatment.

New therapeutic options are being studied for unresponsive forms of the disease, for example plasma exchange [4], immunotherapy [21] or injection of anti-EBV cytotoxic lymphocytes [22].

\section{Conclusions}

Currently, the development of myeloma in a kidney transplant recipient raises several problems related to the lack of specific therapeutic guidelines, the rapid decline of renal 
function (direct effect of myeloma, risk of rejection due to reduced immunosuppressive treatment, chemotherapyrelated nephrotoxicity), and the major risk of infection (immunosuppression, myeloma-related hypogammaglobulinemia, vascular access for dialysis).

In this case report we outline and discuss all of the above problems. First of all, the disease occurred as a de novo glomerulopathy with renal graft failure and nephrotic syndrome. We tried to gather strong arguments to assert the de novo character of MIDD and myeloma which is not always easy. Then, our patient presented the three main risk factors for PTLD which are rarely mentioned in the literature. This raises also the question of EBV reactivation treatment. We illustrated the fact that management strategy is not homogeneous and that clinicians, nephrologists or hematologists, have to face many problems when treating these patients. Last but not least, this case report emphasizes the very bad prognosis of this kind of PTLD that often leads to end-stage renal graft failure and severe infectious complications.

To conclude, a systematic report study of de novo myelomas or plasma cell dyscrasias among kidney transplant recipients would be useful to better define the characteristic features of these patients and to organize large-scale trials to determine a more evidence-based management strategy.

\section{Consent}

Written informed consent was obtained from the patient for publication of this case report and accompanying images. A copy of the written consent is available for review by the Editor-in-Chief of this journal.

\begin{abstract}
Abbreviations
CMV: Cytomegalovirus; EBV: Epstein-Barr virus; HLA: Human leukocyte antigen; MDRD: Modification of Diet in Renal Disease (formula used for the glomerular filtration rate estimation); MIDD: Monoclonal immunoglobulin deposition disease; PTLD: Post-transplant lymphoproliferative disorder.
\end{abstract}

\section{Competing interests}

The authors declare that they have no competing interests.

\section{Authors' contributions}

BS (corresponding author) collected, analyzed and interpreted the patient's data, looked for references from the literature and wrote the manuscript. PA collected, analyzed and interpreted the patient's data and wrote the abstract. $\mathrm{ML}$ and $\mathrm{CH}$ were the clinicians in charge of the patient and provided intellectual content. JC performed all the histological examinations. LF was the investigator of the manuscript project and provided intellectual content. All authors read and approved the final manuscript.

\section{Acknowledgements}

The authors acknowledge the Pathology and Histology Unit of the $\mathrm{CHU}$ Nancy-Brabois and especially Dr Virginie Cahn who performed the in-situ hybridization in the patient's bone marrow aspiration (EBV screening). They acknowledge the Biochemistry Unit of the CHU Nancy-Brabois and especially Dr Christine Jacob for her help collecting the patient's biological data. They acknowledge Mr Wojciech Swiatnicki who revised the manuscript and helped them to improve the English level of the manuscript.

\section{Author details}

${ }^{1} \mathrm{CHU}$ Nancy-Brabois - Service de Néphrologie, Nancy, France. ${ }^{2}$ Hôpital Robert Schuman Metz - Service de Néphrologie, Metz, France. ${ }^{3} \mathrm{CHU}$ Nancy-Brabois - Service d'Hématologie, Nancy, France. ${ }^{4} \mathrm{CHU}$ Nancy-Brabois Service d'Anatomie Pathologique, Nancy, France.

Received: 18 September 2013 Accepted: 7 April 2014

Published: 18 June 2014

\section{References}

1. Harris NL, Ferry JA, Swerdlow SH: Posttransplant lymphoproliferative disorders: summary of Society for Hematopathology Workshop. Semin Diagn Pathol 1997, 14(1):8-14.

2. Ronco PM, Alyanakian MA, Mougenot B, Aucouturier P: Light chain deposition disease: a model of glomerulosclerosis defined at the molecular level. J Am Soc Nephrol 2001, 12(7):1558-1565.

3. Ecder T, Tbakhi A, Braun WE, Tubbs RR, Myles J, McMahon JT: De novo light-chain deposition disease in a cadaver renal allograft. Am J Kidney Dis 1996, 28(3):461-465.

4. Tanenbaum ND, Howell DN, Middleton JP, Spurney RF: Lambda light chain deposition disease in a renal allograft. Transplant Proc 2005, 37(10):4289-4292.

5. Taneda S, Honda K, Horita S, Koyama I, Teraoka S, Oda H, Yamaguchi Y: Light chain deposition disease after renal transplantation. Am J Kidney Dis 2008, 52(no 3):621-625. doi:10.1053/.j.jkd.2008.02.370.

6. Balamuthusamy S, Hamrahian M, Zhang R, Batuman V: Myeloma kidney with isolated tubulointerstitial light chain deposition in a renal allograft. Clin Transplant 2009, 23(6):848-852.

7. Yakupoglu U, Baranowska-Daca E, Rosen D, Barrios R, Suki WN, Truong LD: Post-transplant nephrotic syndrome: a comprehensive clinicopathologic study. Kidney Int 2004, 65(6):2360-2370.

8. Cheigh JS, Mouradian J, Susin M, Stubenbord WT, Tapia L, Riggio RR, Stenzel KH, Rubin L: Kidney transplant nephrotic syndrome: relationship between allograft histopathology and natural course. Kidney Int 1980, 18(no 3):358-365.

9. Caillard S, Agodoa LY, Bohen EM, Abbott KC: Myeloma, Hodgkin disease, and lymphoid leukemia after renal transplantation: characteristics, risk factors and prognosis. Transplantation 2006, 81(6):888-895.

10. Penn I: Neoplastic complications of transplantation. Semin Respir Infect 1993, 8(3):233-239.

11. Ho M, Miller G, Atchison RW, Breinig MK, Dummer JS, Andiman W, Starzl TE, Eastman R, Griffith BP, Hardesty RL: Epstein-Barr virus infections and DNA hybridization studies in posttransplantation lymphoma and lymphoproliferative lesions: the role of primary infection. J Inf Dis 1985, 152(no 5):876-886

12. Pascual J: Post-transplant lymphoproliferative disorder - the potential of proliferation signal inhibitors. Nephrol Dial Transplant 2007, 22(Suppl 1):i27-i35.

13. Strömberg T, Dimberg A, Hammarberg A, Carlson K, Osterborg A, Nilsson K, Jernberg-Wiklund H: Rapamycin sensitizes multiple myeloma cells to apoptosis induced by dexamethasone. Blood 2004, 103(no 8):3138-3147. doi:10.1182/blood-2003-05-1543.

14. Opelz G, Döhler B: Impact of HLA mismatching on incidence of posttransplant non-Hodgkin lymphoma after kidney transplantation. Transplantation 2010, 89(5):567-572.

15. Bakker NA, van Imhoff GW, Verschuuren EAM, van Son WJ, van der Heide JJH, Lems SPM, Veeger NJGM, Kluin PM, Kluin-Nelemans HC, Hepkema BG: HLA antigens and post renal transplant lymphoproliferative disease: HLA-B matching is critical. Transplantation 2005, 80(no 5):595-599.

16. Birkeland SA: Chronic antigenic stimulation from the graft as a possible oncogenic factor after renal transplant. Scand J Urol Nephrol 1983, 17(3):355-359.

17. Ancín I, Sarrá J, Peris J, Romagosa V, Domingo-Claros A, Grañena A: Demonstration of Epstein-Barr virus in a case of multiple myeloma after renal transplantation. Haematologica 2000, 85(7):773-774.

18. Mentzer SJ, Fingeroth J, Reilly JJ, Perrine SP, Faller DV: Arginine butyrate-induced susceptibility to ganciclovir in an Epstein-Barr-virus-associated lymphoma. Blood Cells Mol Dis 1998, 24(2):114-123.

19. Funch DP, Walker AM, Schneider G, Ziyadeh NJ, Pescovitz MD: Ganciclovir and acyclovir reduce the risk of post-transplant lymphoproliferative disorder in renal transplant recipients. Am J Transplant 2005, 5(12):2894-2900.

20. Caillard S, Dharnidharka V, Agodoa L, Bohen E, Abbott K: Posttransplant lymphoproliferative disorders after renal transplantation in the United 
States in era of modern immunosuppression. Transplantation 2005, 80(9):1233-1243.

21. Shapiro RS, Chauvenet A, McGuire W, Pearson A, Craft AW, McGlave P, Filipovich A: Treatment of B-cell lymphoproliferative disorders with interferon alfa and intravenous gamma globulin. N Engl J Med 1988, 318(no 20):1334. doi:10.1056/NEJM198805193182013.

22. Rooney CM, Smith CA, Ng CY, Loftin SK, Sixbey JW, Gan Y, Srivastava DK, Bowman LC, Krance RA, Brenner MK, Heslop HE: Infusion of cytotoxic T cells for the prevention and treatment of Epstein-Barr virus-induced lymphoma in allogeneic transplant recipients. Blood 1998, 92(no 5):1549-1555.

doi:10.1186/1752-1947-8-205

Cite this article as: Savenkoff et al: A de novo monoclonal

immunoglobulin deposition disease in a kidney transplant recipient:

a case report. Journal of Medical Case Reports 2014 8:205.

\section{Submit your next manuscript to BioMed Central and take full advantage of:}

- Convenient online submission

- Thorough peer review

- No space constraints or color figure charges

- Immediate publication on acceptance

- Inclusion in PubMed, CAS, Scopus and Google Scholar

- Research which is freely available for redistribution 